\title{
Volumes de Calda e Adjuvante no Controle de Plantas Daninhas COM GLYPHOSATE ${ }^{1}$
}

\author{
Spray Volume and Adjuvant Effects on Weed Control with Glyphosate
}

\author{
BUENO, M.R. ${ }^{2}$, ALVES, G.S. ${ }^{3}$, PAULA, A.D.M. ${ }^{4}$ e CUNHA, J.P.A.R. ${ }^{5}$
}

\begin{abstract}
RESUMO - O sucesso de uma aplicação de herbicida está diretamente relacionado a uma boa deposição da calda no alvo, com o mínimo de perdas para o ambiente. Assim, o presente trabalho objetivou avaliar a deposição e o controle de plantas daninhas promovido pela aplicação de glyphosate em diferentes volumes de calda e com a adição do adjuvante nonil fenol etoxilado. O experimento foi conduzido em delineamento de blocos casualizados com quatro repetições, em esquema fatorial $3 \times 2$, sendo três volumes de calda (30, 60 e $\left.150 \mathrm{~L} \mathrm{ha}^{-1}\right)$ e duas composições (com e sem adjuvante adicionado ao tanque). Inicialmente, foi realizada a caracterização físico-química das caldas pulverizadas. Foram avaliados, após a aplicação do glyphosate, utilizando pontas de pulverização hidráulicas de jato plano defletor: deposição de calda no alvo, perdas para o solo e controle de plantas daninhas. O adjuvante promoveu alterações de pequena magnitude nas propriedades físico-quimicas da solução. Conclui-se que os menores volumes de calda proporcionaram maiores deposições nas plantas daninhas e menores perdas para o solo. O herbicida estudado proporcionou bom controle das plantas daninhas, independentemente da utilização do adjuvante e do volume de calda.
\end{abstract}

Palavras-chave: deposição de calda, herbicida, propriedades físico-químicas, tecnologia de aplicação.

\begin{abstract}
A successful herbicide application is dependent upon a good spray deposition on the target, with a minimum loss to the environment. Thus, this study aimed to evaluate spray deposition and weed control with glyphosate using different spray volumes and with the addition of the adjuvant nonyl phenol ethoxylate. The experiment was conducted in a randomized block design, in a factorial model 3x2, with three spray volumes $(30,60$, and $150 \mathrm{~L} \mathrm{ha-1)}$ and two spray solution compositions (with and without adjuvant added to the tank). Initially, the physical-chemical properties of the solutions were evaluated under laboratory conditions. Spray deposition, loss to the soil, and weed control were investigated. The adjuvant promoted minor alterations in the physical-chemical properties of the solution. It was concluded that the lowest spray volumes showed the best weed deposition, and the lowest loss for the soil. The adjuvant did not alter the results. The herbicide provided a good weed control irrespective of the volume and adjuvant used.
\end{abstract}

Keywords: spray deposition, herbicide, physical-chemical properties,application technology

\section{INTRODUÇÃO}

As plantas daninhas prejudicam o desenvolvimento e a produtividade de muitos cultivos agrícolas, principalmente pelo fato de competirem com a cultura por água, luz, nutrientes e espaço físico. Os prejuízos em produtividade decorrentes dessa competição devem-se especialmente ao fato de que nas áreas agrícolas as plantas daninhas geralmente ocorrem em densidades bem superiores às das espécies cultivadas (Bianchi et al., 2006).

1 Recebido para publicação em 27.7.2012 e aprovado em 18.12.2012.

2 Doutoranda em Agronomia, Instituto de Ciências Agrárias - ICIAG, Universidade Federal de Uberlândia - UFU, Rua Amazonas, s/n, Umuarama, 38400-902 Uberlândia-MG, Brasil, <marianarb_agro@yahoo.com.br>; ${ }^{3}$ Mestrando em Agronomia, ICIAGUFU, Uberlândia-MG, <guilhermeagro43@yahoo.com.br>; ${ }^{\overline{4}}$ Eng ${ }^{\mathrm{a}}-\mathrm{Agr}{ }^{\mathrm{a}}$., ATM Bayer CropScience, Uberlândia-MG, <alyne_agroufu@hotmail.com>; ${ }^{5}$ Prof., Dr., ICIAG-UFU, Uberlândia-MG, <jpcunha@iciag.ufu.br>. 
A principal forma de controle de plantas daninhas é o controle químico com a utilização de herbicidas sistêmicos ou de contato, aplicados em operações de dessecação, pré e pósemergência. A operação de dessecação tem grande importância para o estabelecimento de uma lavoura, visto que a emergência dessas plantas, juntamente com a cultura, provoca danos tanto na produtividade como na qualidade do produto colhido. Nesse contexto, o glyphosate é um dos herbicidas mais utilizados para o controle de plantas daninhas.

Contudo, a ação dos agrotóxicos é dependente de outros constituintes da calda de pulverização, que, embora não compondo o ingrediente ativo, têm a capacidade de melhorar sua eficácia (Cunha \& Alves, 2009). A adição de adjuvantes à calda pode melhorar em muitos casos o resultado das aplicações, pois eles podem aumentar a aderência e absorção do ingrediente ativo sobre a superfície foliar (Ramsdale \& Messersmith, 2001; Ryckaert et al., 2007), além de reduzir a tensão superficial das gotas (van Zyl et al., 2010). Alguns adjuvantes utilizam em sua formulação uma mistura de aditivos, como óleo mineral ou vegetal, surfatantes não iônicos, sequestrantes de cátions, acidificantes, entre outras substâncias, sendo também conhecidos por adjuvantes multifuncionais (Dan et al., 2010).

No entanto, a interação adjuvante e agrotóxico é um processo complexo que envolve muitos aspectos físico-químicos e fisiológicos, que podem variar de acordo com as condições de cada aplicação (Ramsdale \& Messersmith, 2001; Stainier et al., 2006). Dessa forma, é muito importante conhecer as características físico-químicas das caldas de pulverização de forma a entender a função de seus componentes, uma vez que existe pouca informação a esse respeito e sobre os fatores que as influenciam (De Schampheleire et al., 2008).

Além das características do herbicida e da calda, é essencial também conhecer a tecnologia da aplicação, buscando identificar se o produto está de fato sendo depositado no alvo de forma eficiente, com o mínimo de perdas (Matthews, 2002; Cunha, 2008).

Atualmente, há uma tendência de redução dos volumes de calda, a fim de diminuir os custos de produção e elevar a capacidade operacional das aplicações. O uso de menores volumes aumenta a autonomia e a capacidade operacional dos pulverizadores e diminui o risco de perdas por escorrimento (Rodrigues et al., 2011). Contudo, essa redução pode levar a uma menor cobertura do alvo, comprometendo a eficácia dos tratamentos. Embora já seja prática comum em algumas propriedades, a redução do volume de calda ainda desperta incerteza sobre sua viabilidade e limite minimo.

O presente trabalho objetivou avaliar a perda para o solo, a deposição no alvo e o controle de plantas daninhas promovido pela aplicação de glyphosate em diferentes volumes de calda e com a adição do adjuvante nonil fenol etoxilado. Além disso, objetivou-se realizar a caracterização físico-química das caldas pulverizadas.

\section{MATERIAL E MÉTODOS}

O delineamento experimental utilizado foi de blocos ao acaso (DBC), seis tratamentos e quatro repetições, totalizando 24 parcelas, em esquema fatorial $3 \times 2$, sendo: três volumes de calda $\left(30,60\right.$ e $\left.150 \mathrm{~L} \mathrm{ha}^{-1}\right)$ e duas composições de calda (com e sem o adjuvante nonil fenol etoxilado), conforme detalhamento na Tabela 1.

Com intuito de avaliar o processo de aplicação de herbicida em dessecação de plantas daninhas, foi utilizado o ingrediente ativo glyphosate (produto comercial ZAPP QI, formulação comercial, concentrado solúvel, com $620 \mathrm{~g} \mathrm{~L}^{-1}$ de glyphosate sal potássico) na dose de $3 \mathrm{~L} \mathrm{ha}^{-1}$ de produto comercial, tendo como referencial teórico a instalação futura da cultura do milho. O adjuvante utilizado foi o nonil fenol etoxilado (concentração de $124,4 \mathrm{~g} \mathrm{~L}^{-1}$ ) na proporção de $0,05 \% \mathrm{v} / \mathrm{v}$, indicado como espalhante adesivo.

Previamente aos ensaios de campo, foi realizada a caracterização físico-química das caldas de pulverização empregadas: água + herbicida glyphosate e água + herbicida glyphosate + nonil fenol etoxilado). As avaliações foram feitas considerando a concentração do glyphosate empregada nos três volumes de calda, de forma a manter a mesma dose de 
Tabela 1 - Descrição dos tratamentos e pontas utilizados no ensaio

\begin{tabular}{|c|c|c|c|c|c|}
\hline Tratamento & $\begin{array}{c}\text { Volume de calda } \\
\left(\mathrm{L} \mathrm{ha}^{-1}\right)\end{array}$ & Adjuvante & $\begin{array}{c}\text { Ponta de } \\
\text { pulverização }\end{array}$ & $\begin{array}{c}\text { Pressão de } \\
\text { pulverização }(\mathrm{kPa})\end{array}$ & $\begin{array}{c}\text { Diâmetro de gotas } \\
-\mathrm{DMV}(\mathrm{m}) * *\end{array}$ \\
\hline 1 & 30 & Sem & TT 11001* & 176 & $303(200 \mathrm{kPa})$ \\
\hline 2 & 30 & Com & TT 11001 & 176 & $303(200 \mathrm{kPa})$ \\
\hline 3 & 60 & Sem & TT 11001 & 150 & $334(150 \mathrm{kPa})$ \\
\hline 4 & 60 & Com & TT 11001 & 150 & $334(150 \mathrm{kPa})$ \\
\hline 5 & 150 & Sem & TT 11002 & 270 & $329(300 \mathrm{kPa})$ \\
\hline 6 & 150 & Com & TT 11002 & 270 & $329(300 \mathrm{kPa})$ \\
\hline
\end{tabular}

* TT 11001 e TT 11002: pontas de jato plano defletor. ** DMV - diâmetro da mediana volumétrica na pressão (indicada entre parênteses) mais próxima à empregada no ensaio, de acordo com o fabricante (Teejet, s.d.)

herbicida em todos os tratamentos em campo. Foram avaliados potencial hidrogeniônico, densidade, viscosidade, tensão superficial e estabilidade de soluções, seguindo-se a metodologia empregada por Cunha \& Alves (2009).

Nessa caracterização físico-química das caldas de pulverização, a temperatura das soluções foi mantida a $20 \pm 1{ }^{\circ} \mathbf{C}$.

$\mathrm{O} \mathrm{pH}$ e a condutividade elétrica foram medidos diretamente nas soluções, utilizando peagômetro portátil (Hanna, HI98139). A densidade foi estimada por meio da determinação da massa de $0,1 \mathrm{~L}$ da solução depositada em um balão volumétrico, em balança com resolução de $0,1 \mathrm{mg}$. A viscosidade dinâmica foi determinada empregando-se um viscosímetro rotativo microprocessado (Quimis, Q860M21). A tensão superficial foi determinada utilizando-se um tensiômetro de bancada com anel de platina (Kruss, K6). A estabilidade da calda foi avaliada de forma visual. Após o preparo das soluções e descanso por uma hora, elas foram agitadas homogeneamente por 60 segundos. Posteriormente, após 10, 20, 40, 60 e 120 minutos, verificou-se a formação de fases na solução: estável (monofásica) e instável (bifásica).

No campo, as parcelas experimentais constaram de uma área de $30 \mathrm{~m}^{2}$, sendo $6 \mathrm{~m}$ de comprimento e $5 \mathrm{~m}$ de largura. Como área útil, foram considerados $4 \mathrm{~m}$ de comprimento e $4 \mathrm{~m}$ de largura, resultando em $16 \mathrm{~m}^{2}$. As aplicações foram realizadas em operação de dessecação das plantas daninhas. A área utilizada estava em pousio há quatro meses, sendo o milho a cultura anterior. Aos 15 dias antes de se proceder à dessecação, fez-se a utilização na área de um desintegrador mecânico de palha, modelo Triton, a fim de reduzir o excesso de plantas perenizadas, eliminar restos culturais e favorecer a rebrota das plantas daninhas, obtendo-se, assim, condições ideais para avaliação do herbicida.

Antes da aplicação do herbicida, foi realizada uma estimativa da porcentagem de cobertura do solo pelas plantas daninhas incidentes na área, bem como a determinação do percentual de cada espécie (Tabela 2). Essas plantas encontravam-se em rebrota, após a passagem do desintegrador mecânico, nos estádios vegetativos compreendidos entre V2 e V4. A densidade de infestação (porcentagem de área coberta) encontrada foi de $50 \%$.

As aplicações foram feitas utilizando um pulverizador costal pressurizado por $\mathrm{CO}_{2}$, com uma barra de $2 \mathrm{~m}$ de comprimento, espaçamento entre bicos de $0,5 \mathrm{~m}$ e $0,5 \mathrm{~m}$ em relação ao alvo, nas velocidades de 12,0, 5,5 e $6,0 \mathrm{~km} \mathrm{~h}^{-1}$, para os volumes de $30,60 \mathrm{e}$ $150 \mathrm{~L} \mathrm{ha}^{-1}$, respectivamente. Essas velocidades foram previamente conferidas, medindo-se o tempo gasto no percurso de cada parcela. Empregaram-se pontas de jato plano defletor

Tabela 2 - Porcentagem de infestação das plantas daninhas presentes na área de estudo

\begin{tabular}{|l|c|}
\hline \multicolumn{1}{|c|}{ Planta daninha } & \% de infestação \\
\hline Alternanthera tenella & 70 \\
\hline Malvastrum coromandelianum & 10 \\
\hline Commelina benghalensis & 10 \\
\hline Pannicum maximum & 5 \\
\hline Brachiaria brizantha & 5 \\
\hline
\end{tabular}


fabricadas em polímero. As pontas de pulverização utilizadas, a pressão de trabalho e o DMV informado pelo fabricante (Teejet, s.d.) para as respectivas combinações encontramse na Tabela 1.

As condições climáticas durante as aplicações foram monitoradas por meio de um termo-higroanemômetro: temperatura média de $22,2{ }^{\circ} \mathrm{C}$, umidade relativa do ar de $71,8 \%$ e velocidade do vento entre 2 e $3 \mathrm{~km} \mathrm{~h}^{-1}$.

Para avaliar a deposição da calda do herbicida glyphosate nas plantas daninhas e as perdas para o solo, foi adicionado à calda de aplicação um traçador composto do corante alimentício Azul Brilhante (catalogado internacionalmente pela Food, Drug \& Cosmetic como FD $\&$ C Blue n. 1) na dose de $0,3 \mathrm{~kg} \mathrm{ha}^{-1}$ (ajustandose a quantidade do corante adicionada em função do volume de aplicação empregado), para ser detectado por absorbância em espectrofotometria.

Para isso, foi utilizado um espectrofotômetro (fotômetro fotoelétrico de filtro), com lâmpada de tungstênio-halogênio. A quantificação da coloração foi feita por absorbância em 630 nm, faixa de detecção do corante azul utilizado, conforme metodologia apresentada por Palladini et al. (2005). De acordo com Pinto et al. (2007), o traçador Azul Brilhante é estável por um período de cinco horas de exposição solar.

Após aplicação do herbicida, a avaliação da deposição foi feita por meio de duas amostragens por parcela, coletando-se a parte aérea das plantas daninhas em quadrado medindo $0,20 \times 0,20 \mathrm{~m}$. As plantas foram cortadas rente ao solo e acondicionadas em sacos plásticos, adicionando-se $0,2 \mathrm{~L}$ de água destilada, os quais foram fechados e agitados por 30 segundos e acondicionados em recipientes providos de isolamento térmico e luminoso, para posterior análise no laboratório.

A determinação de perdas de calda para o solo foi feita por meio da distribuição ao acaso de quatro lâminas de vidro $\left(37,24 \mathrm{~cm}^{2}\right.$ cada) por parcela. Após a aplicação e secagem das lâminas, elas foram retiradas e armazenadas em sacos plásticos contendo $0,1 \mathrm{~L}$ de água destilada. O procedimento seguinte foi semelhante ao empregado para as plantas daninhas.
Com o uso da curva de calibração, obtida por meio de soluções-padrão de corante, os dados de absorbância foram transformados em concentração. De posse da concentração inicial da calda e do volume de diluição das amostras, determinou-se a massa de corante retida no alvo. Para o depósito nas plantas daninhas, procedeu-se então à divisão do depósito total pela massa seca da amostra de remoção, obtendo-se, assim, a quantidade em $\mathrm{mg} \mathrm{kg}^{-1}$ de massa seca. As plantas daninhas foram secas em estufa, a $65^{\circ} \mathrm{C}$, por 72 horas. Quanto a perdas para o solo, procedeu-se à divisão do depósito total pela área de remoção das lâminas, obtendo-se a quantidade em $\mu \mathrm{g} \mathrm{cm}^{-2}$.

Após a aplicação, foram realizadas três avaliações visuais de controle, aos 7, 14 e 21 dias após a aplicação (DAA) do herbicida, mediante a escala de avaliação visual de controle de plantas daninhas por meio de herbicida, desenvolvida pela Asociación Latino Americana de Malezas (ALAM, 1974).

$\mathrm{Na}$ análise dos dados, inicialmente foram aplicados os testes de Levene e Shapiro-Wilk para avaliar a homogeneidade das variâncias e a normalidade dos erros, respectivamente, a 0,05 de probabilidade. Posteriormente, eles foram submetidos à análise de variância e, quando pertinente, as médias foram comparadas pelo teste de Tukey a 0,05 de probabilidade.

\section{RESULTADOS E DISCUSSÃO}

Nota-se na Tabela 3 que o $\mathrm{pH}$ das soluções não foi influenciado pelos volumes de calda $\mathrm{e}$ presença do adjuvante. Green \& Beestman (2007) afirmam que a ação dos adjuvantes sobre o $\mathrm{pH}$ é bastante variada, podendo levar ao seu aumento, redução ou inalteração, dependendo de sua composição química.

Ainda na Tabela 3, percebe-se que a maior e a menor densidade foram observadas no menor e no maior volume de calda, respectivamente. Isso pode ser explicado pelo fato de a calda apresentar maior concentração do glyphosate, o que provavelmente resultou nas diferenças de densidade, a qual também foi afetada pelo adjuvante. A presença deste na calda reduziu a densidade da solução. Contudo, a grandeza das alterações foi muito pequena. 
Quanto à viscosidade, nota-se na Tabela 4 que o adjuvante reduziu em média $0,05 \mathrm{mPa} \mathbf{s}$. Para os volumes de calda, a maior viscosidade foi observada na calda que possuía a maior concentração do herbicida, devido ao menor volume aplicado com a mesma dose dos demais tratamentos $\left(3,0 \mathrm{~L} \mathrm{ha}^{-1}\right)$.

Na análise da tensão superficial (Tabela 4), a interação entre volume de calda e adjuvante foi significativa. Verifica-se que a presença do nonil fenol etoxilado reduziu a tensão superficial, sobretudo para os maiores volumes de calda (60 e $150 \mathrm{~L} \mathrm{ha}^{-1}$ ). Quando não se utilizou o adjuvante, a menor tensão superficial foi observada para o menor volume de calda $\left(30 \mathrm{~L} \mathrm{ha}^{-1}\right)$. Nesse caso, provavelmente o que ocasionou essa redução foi a alta concentração do glyphosate na calda. Novamente, embora tenham sido encontradas diferenças significativas, a grandeza das variações foi pequena, sem levar a grandes alterações de ordem prática.

De forma complementar, foram medidas também as tensões superficiais da água e da água + adjuvante, obtendo-se os valores de 72,80 e $38,00 \mathrm{mN} \mathrm{m}^{-1}$, respectivamente. Assim, percebe-se que o nonil fenol etoxilado, quando adicionado à calda contendo glyphosate,

Tabela 3 - Potencial hidrogeniônico e densidade das caldas de pulverização utilizadas na aplicação do glyphosate, em função dos volumes de calda e do uso do adjuvante nonil fenol etoxilado

\begin{tabular}{|c|c|c|c|c|c|c|}
\hline \multirow{3}{*}{$\begin{array}{l}\text { Volume de calda } \\
\qquad\left(\mathrm{L} \mathrm{ha}^{-1}\right)\end{array}$} & \multicolumn{3}{|c|}{$\mathrm{pH}$} & \multicolumn{3}{|c|}{ Densidade $\left(\mathrm{g} \mathrm{cm}^{-3}\right)$} \\
\hline & \multicolumn{3}{|c|}{ Adjuvante } & \multicolumn{3}{|c|}{ Adjuvante } \\
\hline & Com & Sem & Média & Com & Sem & Média \\
\hline 30 & 4,80 & 4,78 & $4,79 \mathrm{~A}$ & 1,0261 & 1,0301 & $1,0281 \mathrm{~A}$ \\
\hline 60 & 4,78 & 4,82 & $4,80 \mathrm{~A}$ & 1,0081 & 1,0083 & $1,0082 \mathrm{~B}$ \\
\hline 150 & 4,77 & 4,87 & $4,82 \mathrm{~A}$ & 0,9991 & 1,0014 & $1,0002 \mathrm{C}$ \\
\hline Média & $4,78 \mathrm{a}$ & $4,82 \mathrm{a}$ & & $1,0111 \mathrm{~b}$ & $1,0133 \mathrm{a}$ & \\
\hline $\mathrm{CV}=1,01 \%$ & & $\begin{array}{l}=0,75 \\
=2,74 \\
\mathrm{~A}=2,5\end{array}$ & & $\mathrm{CV}=0,21 \%$ & $\begin{array}{r}\mathrm{F}_{\mathrm{V}}= \\
\mathrm{F}_{\mathrm{A}} \\
\mathrm{F}_{\mathrm{Vx}}\end{array}$ & \\
\hline
\end{tabular}

Médias seguidas por letras distintas, maiúsculas na coluna e minúsculas na linha, diferem entre si pelo teste de Tukey a 0,05 de probabilidade. $\mathrm{CV}$ : coeficiente de variação; $\mathrm{F}_{\mathrm{V}}$ : valor do $\mathrm{F}$ calculado para o fator volume de calda; $\mathrm{F}_{\mathrm{A}}$ : valor do $\mathrm{F}$ calculado para o fator adjuvante; $\mathrm{F}_{\mathrm{VxA}}$ : valor do $\mathrm{F}$ calculado para a interação entre os fatores volume de calda e adjuvante. * Significativo a 0,05 ; ** Significativo a 0,01 ; ${ }^{\text {ns }}$ Não significativo.

Tabela 4 - Tensão superficial e viscosidade das caldas de pulverização utilizadas na aplicação do glyphosate, em função dos volumes de calda e do uso do adjuvante nonil fenol etoxilado

\begin{tabular}{|c|c|c|c|c|c|c|}
\hline \multirow{3}{*}{$\begin{array}{l}\text { Volume de } \\
\text { calda } \\
\left(\mathrm{L} \mathrm{ha}^{-1}\right)\end{array}$} & \multicolumn{3}{|c|}{ Tensão superficial $\left(\mathrm{mN} \mathrm{m}^{-1}\right)$} & \multicolumn{3}{|c|}{ Viscosidade (mPa s) } \\
\hline & \multicolumn{3}{|c|}{ Adjuvante } & \multicolumn{3}{|c|}{ Adjuvante } \\
\hline & Com & Sem & Média & Com & Sem & Média \\
\hline 30 & $38,73 \mathrm{bA}$ & $39,40 \mathrm{aB}$ & 39,07 & 1,61 & 1,64 & $1,62 \mathrm{~A}$ \\
\hline 60 & $38,53 \mathrm{bB}$ & $39,97 \mathrm{aAB}$ & 39,25 & 1,53 & 1,60 & $1,57 \mathrm{~B}$ \\
\hline 150 & $38,17 \mathrm{bB}$ & $40,37 \mathrm{aA}$ & 39,27 & 1,52 & 1,58 & $1,55 \mathrm{~B}$ \\
\hline Média & 38,48 & 39,91 & & $1,56 \mathrm{~b}$ & $1,61 \mathrm{a}$ & \\
\hline $\mathrm{CV}=0,91 \%$ & \multicolumn{3}{|c|}{$\begin{array}{c}\mathrm{F}_{\mathrm{V}}=0,578^{\mathrm{ns}} \\
\mathrm{F}_{\mathrm{a}}=72,352^{*} \\
\mathrm{~F}_{\mathrm{VxA}}=6,900^{*}\end{array}$} & $\mathrm{CV}=0,75 \%$ & \multicolumn{2}{|c|}{$\begin{aligned} \mathrm{F}_{\mathrm{V}} & =16,187^{*} \\
\mathrm{~F}_{\mathrm{A}} & =18,062^{*} \\
\mathrm{~F}_{\mathrm{V} \times \mathrm{A}} & =0,437^{\mathrm{ns}} ; \sqrt{\mathrm{x}}\end{aligned}$} \\
\hline
\end{tabular}

Médias seguidas por letras distintas, maiúsculas na coluna e minúsculas na linha, diferem entre si pelo teste de Tukey a 0,05 de probabilidade. $\mathrm{CV}$ : coeficiente de variação; $\mathrm{F}^{\mathrm{V}}$ : valor do $\mathrm{F}$ calculado para o fator volume de calda; $\mathrm{F}_{\mathrm{A}}$ : valor do $\mathrm{F}$ calculado para o fator adjuvante; $\mathrm{F}_{\mathrm{VxA}}:$ valor do $\mathrm{F}$ calculado para a interação entre os fatores volume de calda e adjuvante. ${ }^{*}$ Significativo a 0,05 ; ns Não significativo. $\sqrt{x}$ : dados originais transformados por $\sqrt{\mathrm{x}}$ para obter homogeneidade e normalidade pelos testes de Levene e Shapiro-Wilk, respectivamente, a 0,05 de probabilidade. 
não provocou maior redução da tensão superficial. O próprio produto comercial do glyphosate utilizado provavelmente possui adjuvantes com potencial de redução da tensão superficial da calda.

Cunha \& Alves (2009), avaliando diferentes propriedades físico-químicas de soluções aquosas contendo adjuvantes agrícolas, observaram que a adição do nonil fenol etoxilado+ óxido de etileno (120 $\left.\mathrm{g} \mathrm{L}^{-1}\right)$, na dose de $0,15 \% \mathrm{v} /$ $\mathrm{v}$, resultou em $51,1 \mathrm{mN} \mathrm{m}^{-1}$ de tensão superficial. Assim, o nonil fenol etoxilado utilizado por esses autores reduziu a tensão superficial, porém não havia ingrediente ativo nas soluções.

Com relação à estabilidade das soluções, independentemente do volume de calda e do uso do adjuvante, não houve separação de fases nas soluções entre os períodos compreendidos entre 10 e 120 minutos, o que indica uma boa estabilidade da calda. O glyphosate possui alta solubilidade em água, em torno de $10.500 \mathrm{mg} \mathrm{L}^{-1}$ (Milhome et al., 2009), o que explica sua alta estabilidade na solução. Além disso, a baixa concentração do adjuvante faz com que seu efeito sobre a estabilidade da solução seja pequeno.

Sobre o estudo de deposição nas plantas daninhas (Tabela 5), é possivel verificar que os tratamentos com volume de calda de 30 e $60 \mathrm{~L} \mathrm{ha}^{-1}$ produziram maior deposição nas folhas, enquanto o tratamento com $150 \mathrm{~L} \mathrm{ha}^{-1}$ apresentou a menor deposição.

Rodrigues et al. (2011), avaliando a influência do volume de calda (variando de 8,8 a $467 \mathrm{~L} \mathrm{ha}^{-1}$ ) na deposição de glyphosate em plantas daninhas na cana-de-açúcar, concluíram que há possibilidade de utilização de menores volumes sem prejuízo da qualidade dos tratamentos; contudo, as aplicações com volumes inferiores a $190 \mathrm{~L} \mathrm{ha}^{-1}$ foram realizadas com pulverizador dotado de micronizador rotativo com tamanho de gotas controlado, o que difere deste trabalho. Em outro artigo, Souza et al. (2012), estudando a deposição do herbicida 2,4-D em plantas daninhas com diferentes volumes de calda (80 e $130 \mathrm{~L} \mathrm{ha}^{-1}$ ), também concluíram que o menor volume produziu a melhor deposição, porém esses autores não chegaram a estudar volumes inferiores a $80 \mathrm{~L} \mathrm{ha}^{-1}$.
Em contrapartida, Tomazela et al. (2006), avaliando diferentes volumes de calda (variando de 57,37 a 1.147,57 $\mathrm{L} \mathrm{ha}^{-1}$ ) na deposição em Brachiaria plantaginea, observaram que as quantidades de calda depositadas por planta e por $\mathrm{cm}^{2}$ de área foliar foram maiores quando se utilizaram maiores volumes de calda. No entanto, concomitantemente ocorreram maiores perdas para o solo.

Com relação ao uso do adjuvante nonil fenol etoxilado na calda de pulverização, a adição deste não resultou em maior deposição nas plantas daninhas (Tabela 5). Possivelmente, isso ocorreu tendo em vista a pequena magnitude das alterações nas propriedades físico-químicas promovidas pela adição do produto.

Carbonari et al. (2005), estudando a deposição de calda em Cynodon dactylon (gramaseda), obtiveram maior deposição de gotas nas plantas quando foram adicionados adjuvantes à calda, diferentemente do que foi observado neste experimento. Conforme Lan et al. (2007), a adição de adjuvantes à calda de pulverização pode alterar o desempenho das aplicações, porém seu efeito pode ser positivo ou até mesmo negativo no que se refere à deposição do produto, sendo dependente, entre outros fatores, do tipo de produto empregado e das características do alvo.

Ainda na Tabela 5, verificou-se que a adição do adjuvante não resultou em menores perdas de calda para o solo; contudo, observase que, com relação aos volumes de calda, o tratamento com $30 \mathrm{~L} \mathrm{ha}^{-1}$ foi o que apresentou a menor perda para o solo, não diferindo do tratamento com volume de $60 \mathrm{~L} \mathrm{ha}^{-1}$.

Souza et al. (2012) verificaram que o maior volume de calda de $130 \mathrm{~L} \mathrm{ha}^{-1}$ proporcionou maiores perdas para o solo com todas as pontas de pulverização estudadas, quando comparado ao menor volume (80 L ha ${ }^{-1}$ ) na dessecação das plantas daninhas com 2,4-D. Raetano \& Bauer (2004), avaliando perdas por escorrimento na cultura do feijoeiro, também observaram que o maior volume de calda (100 $\mathrm{L} \mathrm{ha}^{-1}$ ) proporcionou maiores perdas para o solo, quando comparado com o menor volume (60 L ha-1), corroborando os resultados obtidos neste trabalho.

Em relação ao uso de adjuvantes na calda, Ramsdale \& Messersmith (2001) afirmam que os adjuvantes melhoram, em muitos casos, a 
Volumes de calda e adjuvante no controle de plantas daninhas ...

Tabela 5 - Deposição de calda nas plantas daninhas (mg de traçador $\left.\mathrm{kg}^{-1}\right)$ e perda para o solo $\left(\mu \mathrm{g}\right.$ de traçador $\left.\mathrm{cm}^{-2}\right)$ após a aplicação do glyphosate em diferentes volumes de calda, com e sem a adição do adjuvante nonil fenol etoxilado

\begin{tabular}{|c|c|c|c|c|c|c|}
\hline \multirow{3}{*}{$\begin{array}{l}\text { Volume de } \\
\text { calda } \\
\left(\mathrm{L} \mathrm{ha}^{-1}\right)\end{array}$} & \multicolumn{3}{|c|}{ Deposição de calda $\left(\mathrm{mg} \mathrm{kg}^{-1}\right)$} & \multicolumn{3}{|c|}{ Perdas para o solo $\left(\mu \mathrm{g} \mathrm{cm}^{-2}\right)$} \\
\hline & \multicolumn{3}{|c|}{ Adjuvante } & \multicolumn{3}{|c|}{ Adjuvante } \\
\hline & Com & Sem & Média & Com & Sem & Média \\
\hline 30 & 442,73 & 427,63 & $435,18 \mathrm{~A}$ & 2,08 & 1,50 & $1,79 \mathrm{~B}$ \\
\hline 60 & 390,57 & 363,76 & $377,17 \mathrm{~A}$ & 2,48 & 2,59 & $2,54 \mathrm{AB}$ \\
\hline 150 & 236,50 & 201,34 & $218,92 \mathrm{~B}$ & 3,12 & 3,03 & $3,07 \mathrm{~A}$ \\
\hline Média & $356,60 \mathrm{a}$ & $330,91 \mathrm{a}$ & & $2,56 \mathrm{a}$ & $2,37 \mathrm{a}$ & \\
\hline $\mathrm{CV}=33,21 \%$ & & $\begin{array}{l}\mathrm{V}=7,692 \\
\mathrm{~A}=0,304^{1} \\
\mathrm{x}=0,01\end{array}$ & & $\mathrm{CV}=25,61 \%$ & $\mathrm{~F}$ & $\begin{array}{l}2^{*} \\
0^{\text {ns }} \\
23^{\text {ns }}\end{array}$ \\
\hline
\end{tabular}

Médias seguidas por letras distintas, maiúsculas na coluna e minúsculas na linha, diferem entre si, pelo teste de Tukey a 0,05 de probabilidade. $\mathrm{CV}$ : coeficiente de variação; $\mathrm{F}_{\mathrm{v}}$ : valor do $\mathrm{F}$ calculado para o fator volume de calda; $\mathrm{F}_{\mathrm{A}}$ : valor do $\mathrm{F}$ calculado para o fator adjuvante; $\mathrm{F}_{\mathrm{vxA}}$ : valor do F calculado para a interação entre os fatores volume de calda e adjuvante. * Significativo a 0,05 ; ${ }^{\text {ns }}$ Não significativo.

eficácia das aplicações; no entanto, a interação adjuvante e agrotóxico é um processo complexo, que envolve muitos aspectos físicos, quimicos e fisiológicos, e varia para cada condição testada, o que pode justificar a não interferência do adjuvante testado nos parâmetros estudados.

Os resultados de deposição nas plantas daninhas e perdas para o solo são complementares, uma vez que o volume que apresentou a maior deposição (30 $\left.\mathrm{L} \mathrm{ha}^{-1}\right)$ foi o mesmo que mostram a menor perda para o solo (Tabela 5), ou seja, as perdas para o solo foram pequenas, pois a maior parte do traçador aplicado ficou retida nas folhas das plantas daninhas.

Assim, é possivel inferir que o uso de menor volume de calda aumenta a autonomia e a capacidade operacional dos pulverizadores, o que tende a reduzir os custos e aumentar o aproveitamento de boas condições climáticas, além de diminuir o risco de perdas por escorrimento. Essa diminuição de perdas por escorrimento significaria, certamente, menor contaminação de águas superficiais (Rodrigues et al., 2011; Souza et al., 2012).

No tocante à eficácia de controle das plantas com o uso do glyphosate, ela não foi influenciada pelo uso de diferentes volumes de calda, nem pela adição ou não do adjuvante nonil fenol etoxilado (Tabela 6). Aos 14 DAA o produto já conseguiu atingir bons índices de controle das plantas daninhas.
Corroborando esse resultado, Galon et al. (2007) afirmam que a variação do volume de calda aplicado (100 e $200 \mathrm{~L} \mathrm{ha}^{-1}$ ) não exerceu interferência na eficácia dos tratamentos herbicidas, empregando vários princípios ativos no controle de plantas daninhas. Costa et al. (2008), ao testarem o efeito de pontas de pulverização na deposição e na dessecação de plantas de Brachiaria brizantha com glyphosate,

Tabela 6 - Controle das plantas daninhas (\%) aos 7, 14 e 21 dias após a aplicação do glyphosate em diferentes volumes de calda, com e sem a adição do adjuvante nonil fenol etoxilado, com base na escala proposta pela ALAM (1974)

\begin{tabular}{|c|c|c|c|}
\hline \multirow{2}{*}{$\begin{array}{l}\text { Volume de } \\
\text { calda } \\
\left(\mathrm{L} \mathrm{ha}^{-1}\right)\end{array}$} & \multicolumn{3}{|c|}{ Controle das plantas daninhas (\%) } \\
\hline & 7 DAA & 14 DAA & $21 \mathrm{DAA}$ \\
\hline 30 & 63,25 & 86,00 & 88,00 \\
\hline 60 & 67,00 & 85,75 & 87,87 \\
\hline 150 & 68,50 & 84,37 & 86,75 \\
\hline \multicolumn{4}{|l|}{ Adjuvante } \\
\hline Sem & 67,17 & 85,91 & 87,00 \\
\hline Com & 67,33 & 85,50 & 86,75 \\
\hline CV $(\%)$ & 16,22 & 14,47 & 6,02 \\
\hline Valores de $\mathrm{F}$ & $\begin{array}{c}\mathrm{F}_{\mathrm{V}}=1,800^{\mathrm{ns}} \\
\mathrm{F}_{\mathrm{A}}=0,600^{\mathrm{ns}} \\
\mathrm{F}_{\mathrm{VxA}}=0,600^{\mathrm{ns}}\end{array}$ & $\begin{array}{c}\mathrm{F}_{\mathrm{V}}=1,707^{\mathrm{ns}} \\
\mathrm{F}_{\mathrm{A}}=2,246^{\mathrm{ns}} \\
\mathrm{F}_{\mathrm{VxA}}=0,629^{\mathrm{ns}}\end{array}$ & $\begin{array}{c}\mathrm{F}_{\mathrm{V}}=1,452^{\mathrm{ns}} \\
\mathrm{F}_{\mathrm{A}}=4,355^{\mathrm{ns}} \\
\mathrm{F}_{\mathrm{VxA}}=1,452^{\mathrm{ns}}\end{array}$ \\
\hline
\end{tabular}

$A$ ausência de letras junto às médias indica que não houve diferença significativa entre tratamentos na análise de variância. CV: coeficiente de variação; $\mathrm{F}_{\mathrm{V}}$ : valor do $\mathrm{F}$ calculado para o fator volume de calda; $\mathrm{F}_{\mathrm{A}}$ : valor do $\mathrm{F}$ calculado para o fator adjuvante; $\mathrm{F}_{\mathrm{vxA}}$ : valor do $\mathrm{F}$ calculado para a interação entre os fatores volume de calda $\mathrm{e}$ adjuvante. ${ }^{\text {ns }}$ Não significativo. 
também afirmam que todas as pontas foram eficientes na dessecação, independentemente do volume utilizado (100 a $200 \mathrm{~L} \mathrm{ha}^{-1}$ ).

Segundo Souza et al. (2007), as plantas daninhas são expostas à pulverização por um tempo extremamente curto, o que, somado a fatores como oscilações de altura da barra, alta velocidade de ventos, diferentes tamanhos de gota e diferentes estádios de desenvolvimento das plantas, implica grande variabilidade dos depósitos unitários obtidos, dificultando a diferenciação de tratamentos.

Para Galon et al. (2007), é possivel afirmar que a eficácia de controle das plantas daninhas por herbicidas sistêmicos ou de contato pode aumentar ou diminuir com a variação do volume de calda aplicado, visto que sua sensibilidade varia em função de fatores intrínsecos à espécie e do ambiente.

Desse modo, em condições adequadas de aplicação podem-se utilizar menores volumes de calda para operação de dessecação com glyphosate, o que reduzirá o tempo gasto na operação e os custos operacionais, sem afetar os niveis de eficácia. Além disso, será obtida também uma economia de água e aumento da capacidade operacional do equipamento de aplicação, devido à redução do número de paradas para reabastecimento (Matthews, 2000; Lima \& Machado Neto, 2001).

Com relação ao uso de adjuvantes, essa não deve ser uma prática generalizada. Segundo Ryckaert et al. (2007), além de se verificar a real necessidade deles, deve-se levar em conta que o aumento na eficiência da aplicação pode causar aumento do impacto ambiental, uma vez que há presença da molécula do adjuvante no ambiente e devido à sua influência no resíduo final do agrotóxico. Com o emprego dos adjuvantes, de forma geral, os períodos de carência devem ser reestudados, em função do aumento dos resíduos dos produtos nos vegetais.

Assim, é possível concluir que o adjuvante nonil fenol etoxilado adicionado à calda de pulverização, em relação à calda somente com glyphosate, promoveu alterações de pequena magnitude nas propriedades físico-químicas da solução. Os menores volumes de calda (30 e $60 \mathrm{~L} \mathrm{ha}^{-1}$ ) promoveram os maiores depósitos nas plantas daninhas e as menores perdas para o solo. O uso do adjuvante não interferiu na deposição de calda. O herbicida glyphosate proporcionou bom controle das plantas daninhas, independentemente dos volumes de calda utilizados e do uso do adjuvante.

Por fim, a redução do volume de calda na aplicação de glyphosate representa uma possibilidade de economia de água e aumento da capacidade operacional do conjunto mecanizado, mantendo a eficácia de controle.

\section{AGRADECIMENTOS}

Ao CNPq e à Fapemig, pelo suporte financeiro parcial, que permitiu o desenvolvimento deste trabalho de pesquisa.

\section{LITERATURA CITADA}

ASOCIACIÓN LATINO AMERICANO DE MALEZAS ALAM. Recomendaciones sobre unificación de los sistemas de evaluación en ensayos de control de malezas. ALAM, v. 1, n. 1, p. $35-38,1974$

BIANCHI, M. A. et al. Proporção entre plantas de soja e plantas competidoras e as relações de interferência mútua. Ci. Rural, v. 36, n. 3, p. 1380-1387, 2006

CARBONARI, C. A. et al. Efeito de surfactantes e pontas de pulverização na deposição de calda de pulverização em plantas de grama-seda. Planta Daninha, v. 23, n. 4, p. $725-729,2005$.

COSTA, N. V. et al. Efeito de pontas de pulverização na deposição e na dessecação em plantas de Brachiaria brizantha. Planta Daninha, v. 26, n. 4, p. 923-933, 2008

CUNHA, J. P. A. R.; ALVES, G. S. Características físicoquímicas de soluções aquosas com adjuvantes de uso agrícola. Interciência, v. 34, n. 9, p. 655-659, 2009.

CUNHA, J. P. A. R. Simulação de deriva de agrotóxicos em diferentes condições de pulverização. Ci. Agrotecnol., v. 32, n. 5, p. 1616-1621, 2008

DAN, H. A. Adjuvantes multifuncionais associados ao herbicida glyphosate no controle de Digitaria insularis. Global Sci. Technol., v. 3, n. 2, p. 30-38, 2010.

DE SCHAMPHELEIRE, M. et al. Effects on pesticide spray drift of the physicochemical properties of the spray liquid.

Prec. Agric., v. 10, n. 5, p. 409-420, 2009.

GALON, L. et al. Controle de plantas e seletividade de herbicidas à cultura da soja, aplicados em dois volume de calda. R. Bras. Agroci., v. 13, n. 3, p. 325-330, 2007. 
LAN, Y. et al. Drift reduction with drift control adjuvants. St. Joseph: ASABE, 2007. 14 p. (Paper, 071060).

LIMA, P. R. F.; MACHADO NETO, J. G. Otimização da aplicação de fluazifop-p-butil em pós-emergência na cultura da soja (Glycine max). Planta Daninha, v. 19, n. 1, p. 85-95, 2001.

GREEN, J. M.; BEESTMAN, G. B. Recently patented and commercialized formulation and adjuvant technology. Crop Protec., v. 26, n. 3, p. 320-327, 2007.

MATTHEWS, G. A. The application of chemicals for plant disease control. In: WALLER, J. M.; LENNÉ, J. M.; WALLER, S. J. (Ed). Plant pathologist's pocketbook. London: CAB, 2002. p. 345-353.

MATTHEWS, G. A. Pesticide application methods. Oxford: Wiley-Blackwell, 2000. 449 p.

MILHOME, M. A. L. et al. Avaliação do potencial de contaminação de águas superficiais e subterrâneas por pesticidas aplicados na agricultura do Baixo Jaguaribe, CE.

Eng. Sanit. Amb., v. 14, n. 3, p. 363-372, 2009.

PALLADINI, L. A. et al. Choice of tracers for the evaluation of spray deposits. Sci. Agríc., v. 62, n. 5, p. 440-445, 2005.

PINTO, J. R. et al. Estabilidade à exposição solar dos traçantes azul brilhante e amarelo tartrasina utilizados em estudos de deposição de pulverização. R. Bras. Agroci., v. 13 n. 1, p. 105-107, 2007.

RAETANO, C. G.; BAUER, F. C. Deposição e perdas da calda em feijoeiro em aplicação com assistência de ar na barra pulverizadora. Bragantia, v. 63, n. 2, p. 309-315, 2004.
RAMSDALE, B. K.; MESSERSMITH, C. G. Nozzle, spray volume, and adjuvant effects on carfentrazone and imazamox efficacy. Weed Technol., v. 15, n. 3, p. 485-491, 2001 .

RODRIGUES, E. B. et al. Cana-de-açúcar: avaliação da taxa de aplicação e deposição do herbicida glyphosate. R. Bras.

Eng. Agríc. Amb., v. 15, n. 1, p. 90-95, 2011.

RYCKAERT, B. et al. Quantitative determination of the influence of adjuvants on foliar fungicide residues. Crop Protec., v. 26, n. 10, p. 1589-1594, 2007.

SOUZA, L. A. et al. Deposição do herbicida 2,4-D amina com diferentes volumes e pontas de pulverização em plantas daninhas. R. Ci. Agron., v. 43, n. 1, p. 78-85, 2012.

SOUZA, R. T. et al. Aspectos metodológicos para análise de depósitos de pulverizações pela determinação dos depósitos pontuais. Planta Daninha, v. 25, n. 1, p. 195-202, 2007.

STAINIER, C. et al. Droplet size spectra and drift effect of two phenmedipham formulations and four adjuvant mixtures. Crop Protec., v. 25, n. 12, p. 1238-1243, 2006.

TEEJET TECHNOLOGIES. Turbo Teejet flat spray tips dropsize. Wheaton: Spraying Systems, [s.d.]. 1 p.

TOMAZELA, M. S. et al. Avaliação da deposição da calda de pulverização em função da densidade populacional de Brachiaria plantaginea, do volume e do ângulo de aplicação. Planta Daninha, v. 24, n. 1, p. 183-189, 2006.

van ZYL, S. A. et al. The use of adjuvants to improve spray deposition and Botrytis cinerea control on chardonnay grapevine leaves. Crop Protec., v. 29, n. 1, p. 58-67, 2010. 